\title{
Introduction to the Special Issue on Agent-Based Computational Economics
}

\section{Christopher S. Ruebeck ${ }^{1} \cdot$ Troy Tassier $^{2}$}

Published online: 20 June 2021

(c) The Author(s), under exclusive licence to Springer Science+Business Media, LLC, part of Springer Nature 2021

Researchers use models of agent-based computational economics (ACE) to study economic systems of heterogeneous interacting agents who are frequently boundedly rational. This paradigm within economics has grown out of roots in other disciplines in the natural and social sciences with an aim to study aspects of complex systems. At its core, ACE takes rules of agent decision making and agent interactions as axioms and observes, through carefully constructed computational experiments, behavior and outcomes of economic and social systems.

The outcomes of these systems grow from the bottom up, without overarching rules confining the system to equilibrium behavior. When an equilibrium occurs within an agent-based model, it occurs from the behavior and learning of agents not as a constraint imposed by the modeler. Thus, market-clearing or other steady-state behavior emerges rather than being defined as a necessary closure of the model. The technique has more flexibility to incorporate complex systems of interactions and networks, behaviors of learning, and diversity of agents. Researchers who use these methods do so in order to attack difficult problems of agent aggregation and learning in markets, to capture distributions of agent outcomes, and to address a host of other difficult problems.

ACE thus moves beyond the requirements of analytical tractability, and in doing so it opens opportunities to study important problems, while maintaining computational tractability. Because of these lessened constraints and opened opportunities, models within ACE can often better incorporate aspects of systems and behavior from other disciplines, feeding cross-disciplinary fertilization of research and knowledge.

Troy Tassier

tassier@fordham.edu

Christopher S. Ruebeck

ruebeckc@lafayette.edu

1 Department of Economics, Lafayette College, Easton, PA 18042, USA

2 Department of Economics, Fordham University, Bronx, NY 10458, USA 
Within this spirit, a small group of researchers from various New York City area universities began meeting at the New School for Social Research in 2004 for biweekly seminars of research presentations. The initial members of this group used the ACE methodology and other methodologies within the field of computational economics.

Over the years this group grew to include additional researchers at universities near NYC. We named ourselves the New York City Computational Economics and Complexity Workshop. When we outgrew our NYC roots we began meeting for a collection of presentations at the venue of the Eastern Economic Association (EEA) annual meeting. These meetings have grown to consistently include 20-30 presentations from multiple continents every year for the past several years.

This special issue collects papers using the ACE methodology. Most are from past participants of our NYC Computational Economics and Complexity Workshop meetings and are frequent contributors since the beginnings of joining the EEA annual meetings. In the papers you will see traditional areas of economics such as public goods, industrial organization, the emergence of money, finance, and macroeconomics addressed with agent-based models. ACE allows researchers to address old problems in new ways and to gain new understandings and knowledge within economics and at its borders with related disciplines. The papers in this special issue are a glimpse into such research.

Publisher's Note Springer Nature remains neutral with regard to jurisdictional claims in published maps and institutional affiliations. 